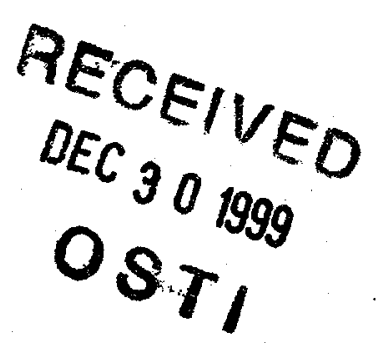

\title{
Graphical Analysis of PET Data Applied to Reversibỉe and Irreversible Tracers
}

\author{
Jean Logan \\ Chemistry Department, Brookhaven National Laboratory \\ Upton, NY 11973
}

Corresponding author:

Jean Logan

Chemistry Department

Brookhaven National Laboratory

Upton, NY 11973

631-344-4391

631-344-7902 (fax)

jlogan@bnl.gov 


\section{Introduction}

Graphical analysis refers to the transformation of multiple time measurements of plasma and tissue uptake data into a linear plot, the slope of which is related to the number of available tracer binding sites. This type of analysis allows easy comparisons among experiments. No particular model structure is assumed, however it is assumed that the tracer is given by bolus injection and that both tissue uptake and the plasma concentration of unchanged tracer are monitored following tracer injection. The requirement of plasma measurements can be eliminated in some cases when a reference region is available. There are two categories of graphical methods which apply to two general types of ligands - those which bind reversibly during the scanning procedure [1] and those which are irreversible or trapped during the time of the scanning procedure $[2,34,5]$.

\section{Graphical analysis of reversible ligands}

For reversible systems the form of the graphical analysis equation can be derived from a general set of compartmental equations [2]

$$
\frac{d \tilde{C}}{d t}=\tilde{K} \tilde{C}+\tilde{K}_{1} C p(t)
$$

Where $\tilde{C}$ is the column vector of concentrations (radioactivities) for each compartment at time $t$, $\tilde{K}$ is the matrix of transfer constants between compartments, and $\widetilde{K}_{1}$ is the vector describing transfer from plasma to tissue (generally there is only nonzero component, $K_{1}$ ), $C p$ is the plasma concentration of the unchanged tracer. Using $R O I(t)=U_{n}{ }^{T} \tilde{C}+V p=\sum_{i} C_{i}(t)+V p C p$, that is, ROI is the sum of radioactivities from all compartments in a given region of interest (ROI) plus a contribution from the regional blood volume $V p,\left(U_{n}\right.$ is a column vector of 1 's), Eq(1) can be rearranged into a linear form (when the second term on the righthand side of $\mathrm{Eq}(2)$ is constant). The individual points are defined by the scanning times $t$

$$
\frac{\int_{0}^{t} R O I\left(t^{\prime}\right) d t^{\prime}}{R O I(t)}=\left(-U_{n}{ }^{T} \tilde{K}^{-1} \tilde{K}_{1}+V p\right) \frac{\int_{0}^{t} C p\left(t^{\prime}\right) d t}{R O I(t)}+\frac{U_{n}{ }^{T} \tilde{K}{ }^{-1} \tilde{C}}{U_{n}{ }^{T} \tilde{C}+V p C p}
$$




\section{DISCLAIMER}

This report was prepared as an account of work sponsored by an agency of the United States Government. Neither the United States Government nor any agency thereof, nor any of their employees, make any warranty, express or implied, or assumes any legal liability or responsibility for the accuracy, completeness, or usefulness of any information, apparatus, product, or process disclosed, or represents that its use would not infringe privately owned rights. Reference herein to any specific commercial product, process, or service by trade name, trademark, manufacturer, or otherwise does not necessarily constitute or imply its endorsement, recommendation, or favoring by the United States Government or any agency thereof. The views and opinions of authors expressed herein do not necessarily state or reflect those of the United States Government or any agency thereof. 


\section{DISCLAIMER}

Portions of this document may be illegible in electronic image products. Images are produced from the best available original document. 
A plot of $\int_{0}^{t} R O I\left(t^{\prime}\right) d t^{\prime} / R O I(t) v s \int_{0}^{t} C P\left(t^{\prime}\right) d t^{\prime} / R O I(t)$ for times $t$ is linear after some time $t^{*}$. The term $-U_{n}{ }^{T} \tilde{K}^{-1} \tilde{K}_{1}$ is the total tissue distribution volume (DV) which for the 2 tissue compartment model

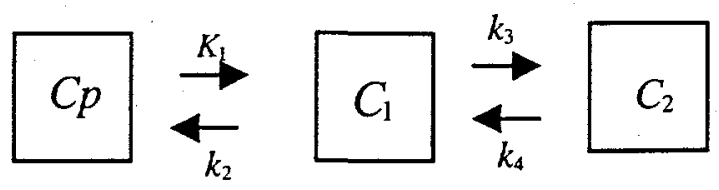

is given by

$$
D V=\frac{K_{1}}{k_{2}}\left(1+\frac{k_{3}}{k_{4}}\right)
$$

The parameter $k_{3}$ is related to the number of (unoccupied) tracer binding sites, and $k_{4}$. is the tracer- binding site dissociation constant. For a 1 compartment model the $\mathrm{DV}$ is $K_{1} / k_{2}$, the ratio of transport constants. Effects of blood flow, capillary permeability and plasma protein binding are implicitly included in $K_{1}$ and $k_{2}$ although their ratio is not a function of blood flow. Nonspecific binding is also included in $k 2$.

The condition for linearity of $\mathrm{Eq}(2)$ is that the intercept (the second term on the righthand side) is constant. For some time $t>t^{\prime} \quad \tilde{C} \rightarrow-\widetilde{K}^{-1} \widetilde{K}_{1} C p$ [2], that is the compartment concentrations follow the plasma concentration. This is the steady state condition. In this case the intercept, $\frac{U_{n}{ }^{T} \tilde{K}^{-1} \tilde{C}}{U_{n}{ }^{T} \tilde{C}+V p C p}$, becomes constant $-\frac{U_{n}{ }^{T} \tilde{K}^{-2} \tilde{K}_{1}}{-U_{n}{ }^{T} \tilde{K}^{-1} \tilde{K}_{1}+V p}$. In many cases the intercept becomes constant even before $C \rightarrow-\widetilde{K}^{-1} \widetilde{K}_{1} C p$, so that the graphical method can be applied before the steady state condition becomes valid, that is for some time $t^{*}<t^{\prime}$. Consider the example (simulated data) in Fig 1. Regions of interest (ROI's) with DV's of 45 (TH) and 12 (CB) are illustrated. Fig $1 \mathrm{~b}$ illustrates the ratio of uptake for these two ROI's (TH/CB). The increasing ratio indicates that the steady state condition has not been reached at least not for the higher DV region. However, the graphical analysis (Fig 1c) is linear and gives the correct DV for both ROI's. To understand why this occurs, consider the intercept for the 2 tissue compartment model which is given by (neglecting the contribution from $V p$ ) 


$$
-\frac{1}{k_{2}}\left[1+\frac{k_{3}}{k_{4}}\right]+\frac{C_{2}(t)}{k_{4}\left(C_{1}+C_{2}(t)\right)}
$$

where $\frac{C_{2}(t)}{C_{1}(t)+C_{2}(t)} \rightarrow \frac{1}{1+k_{4} / k_{3}}$. Table 1 gives the time dependence of $C_{2} /\left(C_{I}+C_{2}\right)$ and $\left(C_{1}+C_{2}\right) / C p$. The latter varies by more than $40 \%$ for times from $35 \mathrm{~min}$ to $115 \mathrm{~min}$ while the former varies only by about $5 \%$ and is effectively constant at 35 to $40 \mathrm{~min}$. Thus the steady state condition is not a requirement for the graphical method to be valid.

The intercepts from the graphical analysis for 1 and 2 compartment models are $-1 / k_{2}$ and $-\left[\left(1 / k_{2}\right)\left(1+k_{3} / k_{4}\right)+1 /\left[k_{4}\left(1+k_{4} / k_{3}\right)\right]\right.$ respectively. Estimates of $K_{1}$ can be made by taking the ratio - slopelintercent This will be valid for the 2 compartment model when the second term in the intercept is small compared to the first.

Figure 2 illustrates simulated data with the same DV but with very different kinetics. For the upper curve (Fig 2a), the main contribution to the DV is from the ratio of transport constants $\lambda=K_{1} / k_{2}$ while for the lower curve the main contribution is from the ratio of binding constants. The graphical analysis is illustrated in Fig $2 b$ Both achieve linearity but with very different times $t^{*}$ which will affect the length of scanning time required to obtain an accurate estimate of the DV.

The distribution volume, which is related to the number of tracer binding sites, has been, found to be estimated with much higher accuracy than individual model parameters [6]. Furthermore comparisons between DV's obtained from a nonlinear least squares (NLLSQ) fit to a particular model and the DV's determined graphically have been found to be in good agreement, for example data from $\left[{ }^{11} \mathrm{C}\right]$ raclopride PET studies in humans using region of interest (ROI) [7]. Koeppe et al compared the graphical analysis to compartmental analysis for ( + )- $\alpha-$ $\left[{ }^{11} \mathrm{C}\right]$-dihydrotetrabenazine (DTBZ) which binds to the vesicular monoamine transporter, finding agreement within 5\% for ROI data [8]. They also found that images constructed using the graphical method and the weighted integral method were essentially equivalent.

The total distribution volume contains within it effects of plasma protein binding $\left(K_{l}\right)$ and nonspecific binding[7]. The kinetic constants for nonspecific binding are assumed to be sufficiently rapid that it is always in a steady state [9] and is implicitly included in model parameters. By taking the ratio of the DV from a ROI with a significant number of binding sites to that of a reference region (devoid of binding sites) we have the distribution volume ratio 
(DVR) given by

$$
D V R=\frac{\frac{K_{1}}{k_{2}}\left(1+\frac{k_{3}}{k_{4}}\right)}{K_{1}^{\text {ref }} / k_{2}^{\text {ref }}}=1+\frac{k_{3}}{k_{4}}
$$

if the ratio of transport constants $\left(K_{l} / k_{2}\right)$ is the same in both regions. In this case the dependence upon plasma protein binding is removed. The DVR is expressed in terms of the ratio of binding constants $\left(k_{3} / k_{4}\right)$ which is related to the binding potential [9]. We have found reproducibility on test/retest is improved when the DVR is used for comparison rather than the DV [10]. It may be that the effects of plasma protein binding are more variable than that of nonspecific binding and this contributes to improved reproducibility. Also the ratio would tend to cancel errors in the metabolite corrsctian $\leqslant$ the plasma input function between experiments.

\section{Distribution Volume Ratios Using a Reference Region (without blood sampling)}

The DVR can be calculated directly with the graphical method by using data from a reference region $(R E F(t))$ with an average tissue to plasma efflux constant, $\bar{k}_{2}$ (to approximate the plasma integral) in Eq (2), 11]

$$
\frac{\int_{0}^{T} R E F(t) d t}{R E F(T)}=\lambda \frac{\int_{0}^{T} C p(t) d t}{R E F(T)}-\frac{1}{k_{2}^{R E F}} \quad \text { where } \quad \lambda=K_{1}^{R E F} / k_{2}^{R E F}
$$

rearranging gives $\quad \int_{0}^{T} C p(t) d t=\frac{1}{\lambda}\left[\int_{0}^{T} R E F(t) d t+\frac{R E F(T)}{k_{2}^{R E F}}\right]$.

Substituting for $\int_{0}^{T} C p d t$ in $\mathrm{Eq}(2)$ gives

$$
\frac{\int_{0}^{T} R O I(t) d t}{R O I(t)}=\frac{D V}{\lambda}\left[\frac{\int_{0}^{T} R E F(t) d t+R E F(T) / k_{2}^{R E F}}{R O I(T)}\right]+\text { int }
$$

Replacing $k_{2}{ }^{R E F}$ with $\bar{k}_{2}$, int becomes int $+\delta$ where $\delta$ is the error term given by

$$
\delta=D V R\left(\frac{1}{k_{2}^{R E F}}-\frac{1}{\bar{k}_{2}}\right) \frac{R E F(T)}{R O I(T)} . \quad \mathrm{DVR}=\mathrm{DV} / \lambda
$$


The analysis equation using the reference region in place of the plasma integral is

$$
\frac{\int_{0}^{T} R O I(t) d t}{R O I(t)}=\frac{D V}{\lambda}\left[\frac{\int_{0}^{T} R E F(t) d t+R E F(T) / \bar{k}_{2}^{R E F}}{R O I(T)}\right]+i n t^{\prime}
$$

When $\left[\frac{D V R}{k_{2}}\right] \frac{R E F(T)}{R O I(T)}$ is small and/or reasonably constant the term containing $\bar{k}_{2}^{R E F}$ in

$\mathrm{Eq}(3)$ can be neglected. Fig. 3 illustrates use of a reference region for $\left[{ }^{11} \mathrm{C}\right]$ raclopride $\left(\bar{k}_{2}=.16\right)$. The upper curve is from an ROI in the basal ganglia which contains specific binding sites. The lower curve is from the cerebellum which does not contain specific binding sites. There is essentially no difference between the DVR calculated with $\bar{k}_{2}=.16$ and with $\bar{k}_{2}=\infty$ (DVR=3.53). Comparing the reference DVR to that calculated from parameters determined from a NLLSQ method (Table 2) we find the DVR greater for the NLLSQ method due to the fact that the reference region has a lower DV than that found by the graphical method. This is because for this subject the 1 compartment model for the reference region (CB) underestimates the DV. For a tracer one particular model structure does not necessarily fit all data sets from a given ROI equally well.

Another example of the DVR calculated from a reference region is taken from a study with the dopamine transporter tracer $\left[{ }^{11} \mathrm{C}\right]$ - $d$-threo-methylphenidate [12] (Fig 4) which has a smaller value of $k_{2}$ than raclopride. The DVR for methylphenidate is much more sensitive to the value used for $\bar{k}_{2}^{\text {REF }}$. From Table 3 with $\bar{k}_{2}=\infty$ the DVR is $15 \%$ less than that calculated by using blood data, using the average value of $k 2$, the DVR is only $5 \%$ less. For comparison the graphical and NLLSQ methods using the plasma input function give equivalent results but somewhat higher than the reference method.

Ichise has proposed an alternative to $\mathrm{Eq}(3)$ which is a multilinear regression [13]. This method appears to provide the same results as $\operatorname{Eq}(3)$ with $\bar{k}_{2}=\infty \quad[14]$

\section{Graphical Analysis of Irreversible Ligands}

Irreversibly binding ligands are essentially trapped for the time course of the scanning procedure. In terms of the 2 compartment model pictured above $k_{4}=0$ so that tracer in $C_{2}$ is trapped. Patlak et al [2] has shown that the rate constant $(K i)$ for the transfer of tracer from 
plasma to the irreversible compartment can be calculated from the equation

$$
\frac{R O I(T)}{C p(T)}=K i-\frac{\int_{0}^{T} C p(t) d t}{C p(T)}+(V e+V p)
$$

which is linear for the times $T>t$ ' when $V e$, the distribution volume of the reversible part (the ratio of the sum of the reversible compartments to the plasma $\sum_{i}{ }^{R E V} \mathrm{Ci} / \mathrm{Cp}$ ) is constant. An ROI from a study with [11C]L deprenyl-D2 is illustrated in Fig 5a and the irreversible graphical analysis in Fig5b. L deprenyl is a suicide inhibitor of the enzyme monoamine oxidase B (MAO B) [15]. We will use this to illustrate some of the difficulties involved in analyzing data from irreversioiy vinuing ligands. The process of enzyme inactivation is a multistep process: drug passes into tissue, forms a complex with the enzyme from which an intermediate is produced ending in a labeled (inactivated) covalently modified enzyme. We cannot separately identify all the individual rate constants involved since we have only the total tissue radioactivity so we cast this in terms of the 2 compartment model (Fig 6) where $k_{3}$ now represents a composite of several steps in the inactivation process. This is generally true of PET models, that is that the processes are more complex than the models we can use. In terms of the 2 compartment irreversible model, the influx constant $K i$ can be expressed as

$$
K i=\frac{K_{1} k_{3}}{k_{2}+k_{3}}=\frac{K_{1} \lambda k_{3}}{K_{1}+\lambda k_{3}}
$$

where $k_{3}$ is the model parameter associated with the enzyme concentration. We have expressed $K i$ in terms of 2 parameters, $K_{I}$ which represents the transport of ligand from plasma to tissue and the combination parameter $\lambda k 3$ which also contains the ratio of transport constants $\left(\lambda=K_{1} / k_{2}\right)$. Although $K_{1}$ and $k_{2}$ are functions of blood flow, $\lambda$ is not. From Eq(3) we can see that $K i$ depends upon $K_{l}$ (blood flow) as well as enzyme concentration (contained in $\lambda k 3$ ). Therefore in order to extract a parameter independent of blood flow it is necessary to determine $K_{1} . \lambda k 3$ can then be determined from $\mathrm{Eq}(3)$

$$
\lambda k_{3}=\frac{K_{1} K i}{K_{1}-K i}
$$

A second difficulty encountered in the analysis of data from irreversible ligands is evident in $\mathrm{Eq}(5)$ and that is that $K_{l}$ must be sufficiently greater than $K i$. that they can both be determined 
with some confidence. Otherwise, if $K_{l} \sim K i$, (which occurs when the trapping rate $\left(k_{3}\right)$ is much greater than $K_{I}$ ) the ligand is said to be flow limited which means that only one parameter can be determine, $K_{I}$, and no information can be obtained about enzyme concentration. Figure 7 illustrates two uptake curves from [ $\left.{ }^{11} \mathrm{C}\right] \mathrm{L}$-deprenylH2 and deuterium substituted $\left[{ }^{11} \mathrm{C}\right] \mathrm{L}-$ deprenylD2 in the same subject. The difference between $K_{I}$ and $K i$ is significantly greater for the $\mathrm{D} 2$ compound than for the $\mathrm{H} 2,0.3$ and 0.12 respectively. In other regions of interest with higher MAO B concentration the $\mathrm{H} 2$ difference was found to be even smaller. The sensitivity of $\mathrm{H} 2$ to differences in MAO B concentration is much less than for the D2 ligand. This leads to greater variability in model parameters regardless of the method of estimation. The substitution of deuterium for hydrogen at the reactive site increased the sensitivity by decreasing the rate of trapping. This is an example of the kinetic isotope effect in which the increased mass of the atom involved in the reaction slows the reaction rate [15].

The estimation of $K_{I}$ can be made by an iterative nonlinear method using the previously determined $K i$ to eliminate one parameter

$$
\begin{gathered}
\frac{d C_{1}}{d t}=K_{1} C p(t)-\left(k_{2}+k_{3}\right) C_{1}=K_{1} C p(t)-\frac{K_{1} k_{3}}{K i} C_{1} \\
\frac{d C_{2}}{d t}=k_{3} C_{1}
\end{gathered}
$$

The number of parameters to be determined can be further reduced by assuming a value for $\lambda$ and using $\mathrm{Eq}(5)$ for $k 3$. This leaves only $K_{l}$ to be determined which can be accomplished in relatively few iterations using only the first part of the uptake curve which is more sensitive to variations in $K_{l}$. In the case of [11C]L-deprenyl, an average estimate of $\lambda$ could be made from blocking studies [16], although an estimate could also be made from regions with lower

concentrations of enzyme (binding sites).

Another alternative is to use a linearized form of the equations (adapted from Blomqvist [17]) 


$$
\begin{aligned}
& R O I(T)=K_{1} \int_{0}^{T} C p(t) d t+\left(k_{2}+k_{3}\right) Z(T) \\
& Z(T)=K i \int_{0}^{T} \int_{0}^{t} C p\left(t^{\prime}\right) d t^{\prime} d t-\int_{0}^{T} R O I(t) d t
\end{aligned}
$$

where $\mathrm{Z}(\mathrm{T})$ can be calculated separately once $K i$ is determined using the method of Patlak. $K_{I}$ can then be calculated from a bilinear regression. Only the early time points were used to solve for $K_{I}(\mathrm{~T}<15 \mathrm{~min}) . \lambda k 3$ calculated by the NLLSQ method (iteratively optimizing all 3 model parameters) was found to be in good agreement with the value obtained using $K i$ and the linearized equations above for ROI data from test/retest studies with L-deprenyl-D2[18]. It was alen fond that there was less variability in $\lambda k 3$ than in $k_{3}$ so that the combination parameter like the DV is more reliably estimated than the individual model parameter.

Wong has used a graphical analysis for the estimation of model parameters for the dopamine D2 ligand [ "C]N-methylspiperone (NMSP) which appears to bind irreversibly over the period of the experiment. In the case of NMSP there are reference regions such as the cerebellum without specific binding $[4,5]$. The analysis equation

$$
V(T)=\alpha \theta(T)+\beta\left(1-e^{-\theta(T) / \tau}\right) .
$$

also uses the normalized time integral of plasma radioactivities $\left(\int_{0}^{T} C p(t) d t / C p(T)\right)$ and the tissue plasma ratio $(V(T)$ ). .From the reference region, $\lambda$ is determined (as $\beta$ when . $V(T)=R E F(T) / C p(T))$. The transition of $V(T)$ vs $\Theta(\mathrm{T})$ to a linear phase at later times is determined by $\tau$. The model parameters $k_{2}$ and $k_{3}$ are determined from $\alpha, \beta$, and $\tau$. $K_{I}$ was assumed to be the same for both reference region and the region of interest [4]. Wong also introduced a ratio index which is the plot of radioactivity in a region of irreversible binding to that in the reference region vs time as opposed to the normalized time [5]. This was found to be linear in the case of NMSP.

\section{Removing the bias in parameter estimates from linear methods}

The linear form of the 1 tissue compartment model is (for scan times $t i$ )

$$
C\left(t_{i}\right)=K_{1} \int_{0}^{t_{i}} C p d t-k_{2} \int_{0}^{t_{i}} C_{1}(t) d t+\xi_{i}
$$


where the equation errors, $\xi_{i}$, are not statistically independent since each succeeding one depends upon the previous ones (at the earlier time points) [19]. This may result in biased parameter estimates. In order to illustrate this problem, the 2 compartment model with parameters given in Figure 8 (uptake illustrated by the solid line) was used to generate 500 data sets with random noise (an example is shown in Fig $8(\vartheta)$ ). The formula used for noise generation (Fig 8) was chosen so that a greater contribution of noise was included in the shorter earlier scans which is what is typically observed. The true DV is 12 , from Figure 9 the distribution of DV's determined using the graphical (Fig 9a) and nonlinear least squares methods (Fig $9 \mathrm{~b}$ ) are shown. The average DV from the graphical was 11.8 and from the NLLSQ method $\therefore \%$. Although this is actually a small difference, it does illustrate the trend that tr $\cdots \cdots$ graphical method underestimates the DV in the presence of noise. Furthermore this underestimate increases as the DV increases[20].

In order to overcome the bias problem in the solution of the 1 compartment model of $\mathrm{Eq}(6)$, Feng [19] introduced a generalized least squares (GLS) method which removes the bias. The GLS form of of $\mathrm{Eq}(6)$ is now

$$
C_{1}\left(t_{i}\right)-\hat{k}_{2} e^{-\hat{k}_{2} t_{i}} \otimes C_{1}\left(t_{i}\right)=K_{1} e^{-\hat{k}_{2} t_{i}} \otimes C_{1}\left(t_{i}\right)-k_{2} e^{-\hat{k}_{2} t_{i}} \otimes C_{1}\left(t_{i}\right)
$$

where $\otimes$ denotes convolution.. This can be written in matrix form as

$$
R=Z \theta
$$

where $\theta^{T}=\left[K_{1}, k_{2}\right]$. and

$$
R=\left[\begin{array}{c}
C_{1}\left(t_{1}\right)-\hat{k}_{2} \int_{0}^{t_{1}} C_{1}(t) e^{-\hat{k}_{2}\left(t_{1}-t\right)} d t \\
\vdots \\
C_{1}\left(t_{n}\right)-\hat{k}_{2} \int_{0}^{t_{n}} C_{1}(t) e^{-\hat{k}_{2}\left(t_{n}-t\right)} d t
\end{array}\right] \quad Z=\left[\begin{array}{c}
\int_{0}^{t_{1}} C p(t) e^{-\hat{k}_{2 t}} d t, \int_{0}^{t_{1}} C_{1}(t) e^{-\hat{k}_{2}\left(t_{1}-t\right)} d t \\
\vdots \\
\int_{0}^{t_{n}} C p(t) e^{-\hat{k}_{2} t_{n}} d t, \int_{0}^{t_{n}} C_{1}(t) e^{-\hat{k}_{2}\left(t_{n}-t\right)} d t
\end{array}\right]
$$

The solution is

$$
\hat{\theta}=\left(Z^{T} Z\right)^{-1} Z^{T} R
$$

The parameter $\hat{k}_{2}$ is an initial estimate which can be obtained from an analysis of the noisy data either by solution of $\mathrm{Eq}(6)$ or by graphical analysis ( $-1 /$ intercept from the graphical analysis of $\mathrm{Eq}(2)$ provides an estimate of an effective $k_{2}$ ). The new value of $k_{2}$ is obtained from $\mathrm{Eq}(7)$. This 
can be repeated for a few iterations.

If the data can be described adequately by a 1 tissue compartment model, then this method provides an easy way to estimate the DV without the bias due to noise. It also offers a potential solution for removing the noise in the graphical method. By applying the GLS method for 1 compartment to the data in two parts, that is determine one set of parameters for times 0 to $t_{l}$ and a second set of parameters for $t_{j}$ to the end, the simple GLS model of Eq(6) can be made to describe data from more complex models in effect generating a smoothed data set. This is illustrated in Fig 10 for the data of Fig 8. In this case 3 parameters were used to fit the first part of the curve. The third parameter was a small constant value entering into $\mathrm{Eq}(6)$ as $B e^{-\hat{k}_{2} t}$. The $\therefore \cdots$ averaged value is recovered when the graphical analysis is applied to this "smoc shes" $A .4$. (Fig 9b). The GLS method has also been extended to multicompartment models which may also be useful in parameter estimation of noisy data [21].

\section{Conclusions}

Graphical methods provide a quick, visual way to obtain information about the kinetics of tracer binding. In some cases these methods can be used without blood sampling if a suitable reference region is available. They do not require a particular model structure. This is an advantage since in practice one model may not fit all data from a particular ROI in a given.study equally well. The problem with the linear type analyses is that they can introduce a bias into parameter estimates. particularly for ligands with large DV's. In the case of irreversibly binding ligands it is generally not sufficient to rely on a graphical analysis alone since it is important to separate tracer delivery (blood flow) from binding. However the graphical analysis can facilitate the estimation of the important model parameters.

\section{Acknowledgments}

Support was provided by Brookhaven National Laboratory under contract DE-AC02$98 \mathrm{CH} 10886$ and with the U. S. Department of Energy and by its Office of Biological and Environmental Research and by the National Institutes of Health grant NS15380. 


\section{REFERENCES}

1. Logan J, Fowler JS, Volkow ND, Wolk AP, Dewey SL, Schlyer DJ, Macgregor RR, Hitzmann R, Bendriem B, Gatley SJ, Christman DR (1990) Graphical analysis of reversible radioligand binding from time-activity measurements applied to [N-11C-methyl-(-)-cocaine PET studies in human subjects. J Cereb Blood Flow Metab 10:740-747.

2. Patlak C, Blasberg RG, Fenstermacher JD (1983) Graphical evaluation of blood-to-brain transfer constants from multiple-time uptake data. J Cereb Blood Flow Metab3:1-7.

3. Patlak C, Blasberg RG (1985) Graphical evaluation of blood-to-brain transfer constants from multiple-time uptake data. Generalizations. J Cereb Blood Flow Metab 5:584-590.

4. Wong DF, Young D, Wilson PD, Meltzer CC, Gjedde A (1997) Quantification of neuroreceptors in the living human brain: IV. Effect of aging and elevations $=\mathbf{f}: 2: \ldots 2$ receptors in schizophrenia and bipolar illness $J$ Cereb Blood Flow Metab 17:331-342.

5. Wong DF, Gjedde A, Wagner HN Jr (1986) Quantification of neuroreceptors in the living hyman brain. I. Association rate of irreversibly bound ligands J Cereb Blood Flow Metab 6:137146.

6. Carson RE, Channing MA, Blasberg RG, Dunn BB, Cohen RM, Rice KC, Herscovitch P (1993) Comparison of bolus and infusion methods for receptor quantification: application to $\left[{ }^{18} \mathrm{~F}\right]$ cyclofoxy and positron emission tomography. ligands $J$ Cereb Blood Flow Metab 13:24-42.

7 Logan J, Volkow, Fowler JS, Wang G-J, Dewey SL, MacGregor R, Schlyer D, Gatley SJ, Pappas N,King P, Hitzemann, Vitkun S (1994) Effects of blood flow on [11C]raclopride binding in the brain: Model simulations and kinetic analysis of PET data. J Cereb Blood Flow Metab 14:995-1010.

8. Koeppe RA, Frey KA, Kume A, Albin R, Kilbourn MR, Kuhl DE (1997) Equilibrium versus compartmental analysis for assessment of the vesicular monoamine transporter using $(+)$-alpha[11C]dihydrotetrabenazine (DTBZ) and positron emission tomography $J$ Cereb Blood Flow Metab 17: 919-931.

9. Mintun MA, Raichle ME, Kilbourn MR, Wooten GF, Welch MJ (1984) A quantitative model for the invivo assessment of drug binding sites with positron emission tomography Ann Neurol 15:217-227.

10. Volkow ND, Fowler JS, Wang G-J, Dewey SL, Schlyer D, MacGregor R, Logan J, Alexoff D, Shea C, Hitzemann R, Angrist B, Wolf A (1993). Reproducibility of repeated measures of carbon-11-raclopride binding in the human brain $J$ Nucl Med 34:609-613. 
11. Logan J, Fowler JS, Volkow ND, Wang G-J, Ding YS, Alexoff DL (1996) Distribution volume ratios without blood sampling from graphical analysis of PET data J Cereb Blood Flow Metab 16:834-840.

12. Volkow ND, Ding YS, Fowler JS, Wang G-H, Logan J, Gatley SJ, Schlyer DJ, Pappas N (1995) A new PET ligand for the dopamine transporter: Studies in the human brain. $J$ Nucl Med $36,2162-2168$.

13. Ichise M, Ballinger JR, Golan H, Vines D, Luong A, Tsai S, Kung HF (1995) SPECT imaging of dopamine D2 receptors in humans with iodine 123-IBF: a practical approach to quantification not requiring blood sampling. $J$ Nucl Med 36:11P

14. Logan J (1996) From graphical analysis to multilinear regression analysis of reversible radioligand binding (Letter to the editor) J Cereb Blood Flow Metab 16:750.757

15. Fowler JS, Wolf, AP, MacGregor RR, Dewey SL, Logan J, Schlyer DJ, Langstrom B (1988) Mechanistic positron emission tomography studies: demonstration of a deuterium isotope effect in the monoamine oxidase catalyzed binding of [11C]L-deprenyl in living baboon brain $J$ Neurochem 51:1524-1534.

16. Fowler JS, Volkow ND, Logan J, Schlyer D, MacGregor RR, Wang G-J, Wolf AP, Pappas N, Alexoff D, Shea C, Gatley SJ, Dorflinger E, Yoo K, Kruchowy L, Fazzini, (1993) Monoamine oxidase B (MAO B) inhibitor therapy in Parkinson's disease: the degree and reversibility of human brain MAO B inhibition by Ro 196327 Neurology 43; 1984-1992.

17. Blomqvist $\mathrm{G}$ (1984) On the construction of functional maps in positron emission tomography J Cereb Blood Flow Metab 4:629-632.

18 Logan J, Fowler JS, Volkow ND, Wang G-J, MacGregor RR, Shea C (1999) Reproducibility of repeated measures of deuterium substituted $\left[{ }^{11} \mathrm{C}\right] \mathrm{L}$-deprenyl $\left(\left[{ }^{1 !} \mathrm{C}\right] \mathrm{L}\right.$-deprenyl-D2) binding in the human brain. Nucl Med and Biol (submitted).

19. Feng D, Wang Z, Huang SC, (1993) A study on statistically reliable and computationally efficient algorithms for the measurement of local cerebral blood flow with positron emission tomography IEEE Trans Med Imag 12:182-188.

20 Slifstein M, Laruelle M (1999) Statistical bias in the Logan graphical method. J Nucl Med 40:35P.

21. Feng D, Huang S-C, Wang ZZ, Ho D (1996) An unbiased parametric imaging algorithm for nonuniformly sampled biomedical system parameter estimation IEEE Trans Med Imag 15:512518. 
Figure captions:

Figure 1. a. Simulated data - upper curve (TH) has a $D V=45$, lower curve (CB) $D V=12$. b. Ratio of uptake TH/CB. c. Graphical analysis of data in a.

Figure 2: a. Both curves (simulated data) have the same DV but very different kinetics. The model parameters are given. b. Graphical analysis of the data in (a) indicating a diffference in $t^{*}$, the initial time at which the analysis becomes linear.

Figure 3. a.. PET study with $\left[{ }^{11} \mathrm{C}\right]$ raclopride. The upper curve is an $\mathrm{ROI}$ from the basal ganglia (BG) and the lower curve is a reference region from the cerebellum (CB). b. Graphical analysis using $\mathrm{CB}$ as the reference region, $\bar{k}_{2}=.16 \mathrm{~min}-1, \mathrm{DVR}=3.52$.

Figure 4. a.. PET study with $\left[{ }^{11} \mathrm{C}\right]$ methylphenidate $-(\mathrm{BG})(\diamond)$ and $\mathrm{CB}(\diamond)$. b. Graphical analysis using a reference region $\vec{k}_{2}=0.05 \mathrm{~min}-1, \mathrm{DVR}=2.59$.

Figure 5. a. Regional uptake data from a PET study with $\left[{ }^{11} \mathrm{C}\right] \mathrm{L}$-deprenyl-D2, an irreversible MAO B inibitor. b. Graphical analysis for irreversible ligands, $K i=0.12 \mathrm{~min}-1$.

Figure 6. The accepted model for enzyme inactivation and the 2 tissue compartment model actually used for describing the binding of L-deprenyl.

Figure 7. Regional uptake for $\left[{ }^{11} \mathrm{C}\right] \mathrm{L}-$ deprenyl-H2 $(\diamond)$ and $\left[{ }^{11} \mathrm{C}\right] \mathrm{L}$-deprenyl-D2 $(\diamond)$ in the same individual. $K_{1}$ is the same for both $\left(K_{1}(\mathrm{H} 2)=.41 \mathrm{~min}-1, K_{1}(\mathrm{D} 2)=.42 \mathrm{~min}-1\right)$ therefore the difference is due to the trapping rate $\left(k_{3}\right)$ which is reduced in the $\mathrm{D} 2$ compoiund due to the isotope effect. As a result the $K i$ for D2 is .12 and $K i$ for $\mathrm{H} 2$ is $.29 \mathrm{~min}-1$. The sensitivity of the D2 compound to changes in MAO B concentration is much greater than that of deprenyl-H2.

Figure 8. Data generated from the 2 tissue compartment model $(\mathrm{DV}=12)$ with $K_{1}=0.6, k_{2}=0.2$, $k_{3}=0.1, k_{4}=0.033(\min -1)$. The solid line represents the data without random noise $(\mathrm{ROI}(\mathrm{t}))$ and 
the symbols represent data generated with random noise $R O I_{N}(t)=R O I(t)+d e v$ where $d e v=(.5-x x) s c \sqrt{\frac{R O I(t)}{\Delta t}}, s c=15$ (scale factor), and $\mathrm{xx}$ is a pseudorandom number from 0 to 1. $\Delta t$ is the scan length.

Figure 9. a. The distribution of DV determined using the graphical method from simulated data with random noise $(\mathrm{N}=500)$. b. The distribution of DV's determined by using the nonlinear least squares method of fitting 4 parameters to the 2 tissue compartment model.

Figure 10. a. "Smoothed" data (solid diamonds) generated from a slightly modified version of Feng's GLS method for a 1 compartment model. The original data with random noise are indicated by open diamonds. b. Distribution of DV's from the "smoothed" data set 


\section{Table headings}

Table1: A comparison of the ratio of compartment concentrations (specifically bound compartment $(\mathrm{C} 2)$ to the total $(\mathrm{C} 1+\mathrm{C} 2)$ ) and the tissue to plasma ratio (which approaches a constant value in the steady state) vs time for the data shown in Fig la $(\diamond)$.

Table 2. A comparison of the DV's computed graphically (GR) and by the NLLSQ methods for the ROI's BG ( ) and CB $(\diamond)$ (Fig 3a) for $\left[{ }^{11} \mathrm{C}\right]$ raclopride. The DVR for both GR and NLLSQ methods are compared with the DVR from a reference region (CB).

Table 3. A comparison of the DV's computed graphically (GR) and by the NLLSQ methods for the ROI's BG $(\diamond)$ and $\mathrm{CB}(\diamond)$ (Fig 3a) for $\left[{ }^{11} \mathrm{C}\right] d$-threo-methylphenidate. The DVR for both GR and NLLSQ methods are compared with the DVR from a reference region $(\mathrm{CB})$ using an average $k 2\left(\bar{k}_{2}\right)$. The variation of DVR $\mathrm{REF}$ with $k_{2}$ is also shown. 


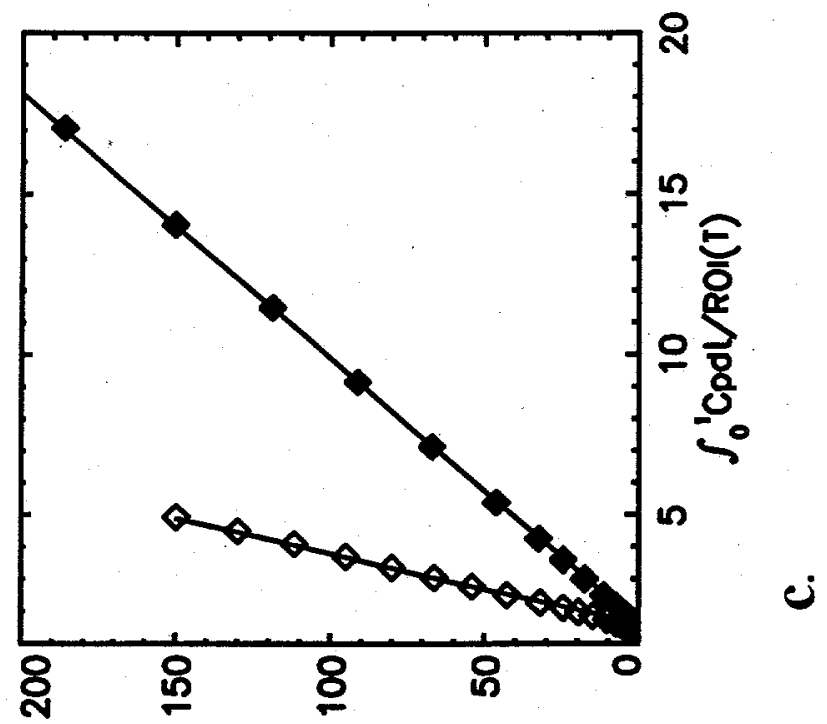

(1)108/7P1O4

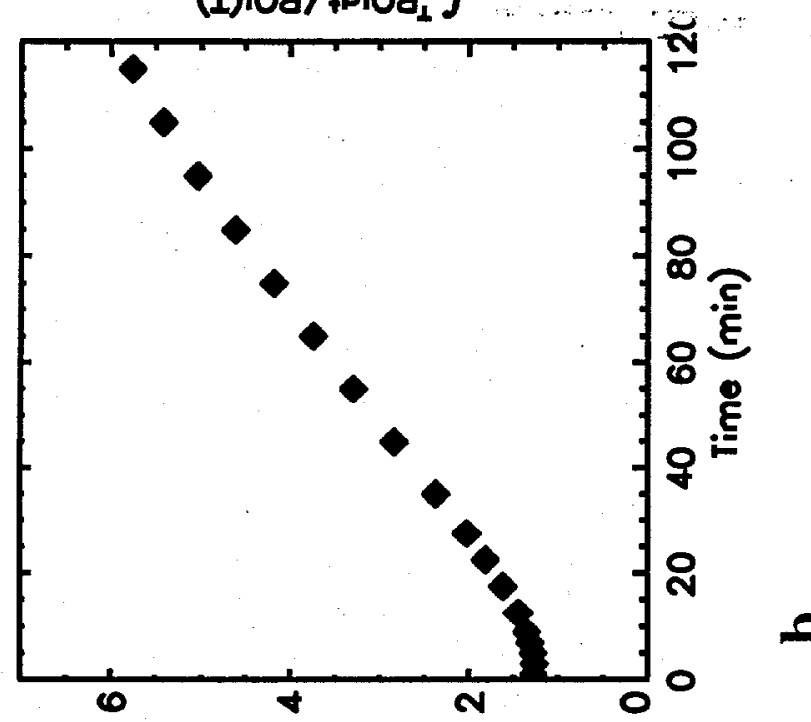

8J/HI

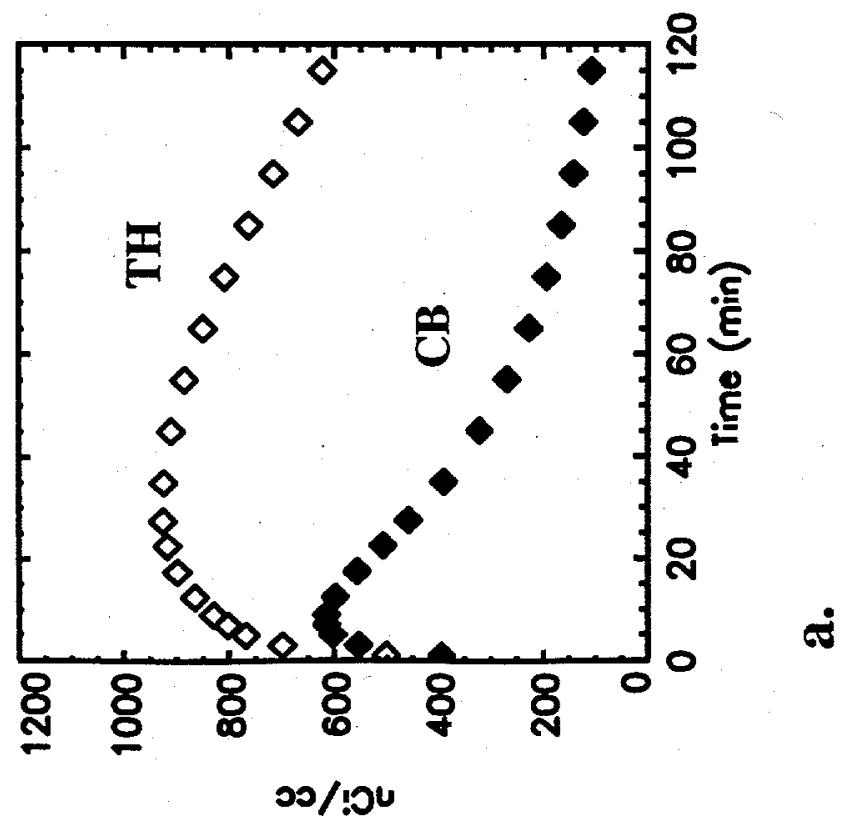



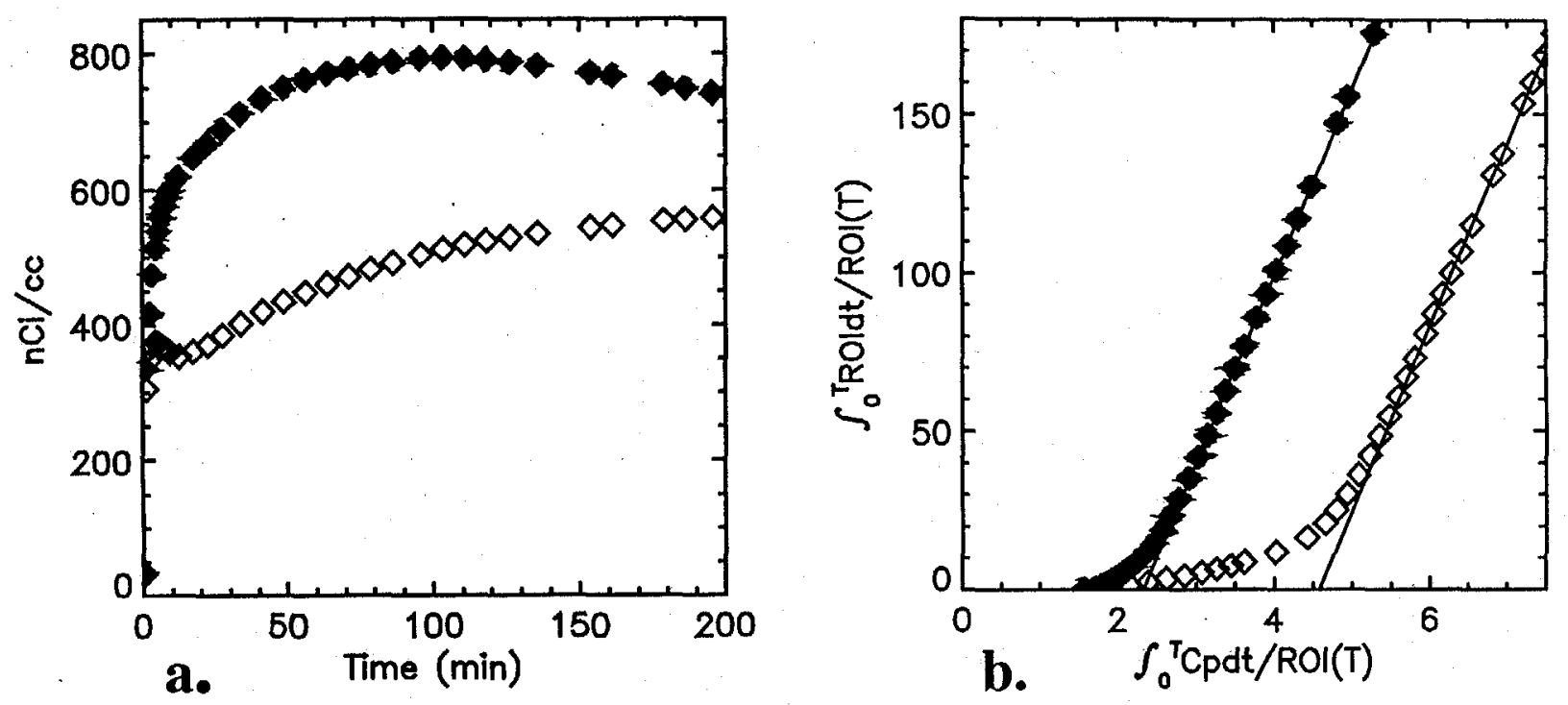

$\begin{array}{rrrrrrrr} & \lambda & K_{1} & k_{3} & k_{4} & k_{3} / k_{4} & D V \\ \diamond & 3.0 & .6 & .1 & .005 & 20 & 60 & \mathbf{t}^{*}=80 \\ \diamond & 10 . & .5 & .1 & .02 & 5.0 & 60 & \mathbf{t}^{*}=35\end{array}$

Figure 2 

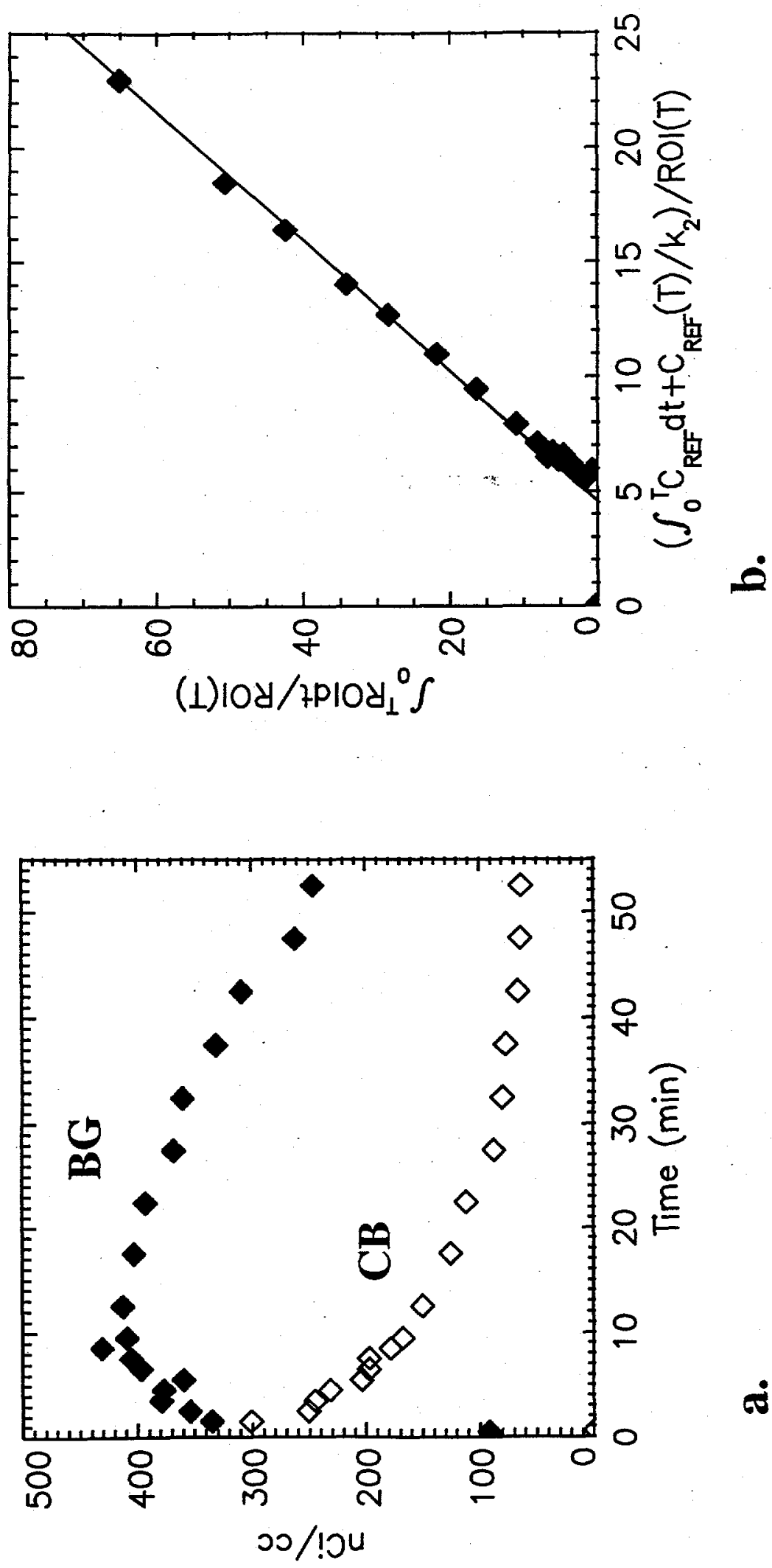

总 


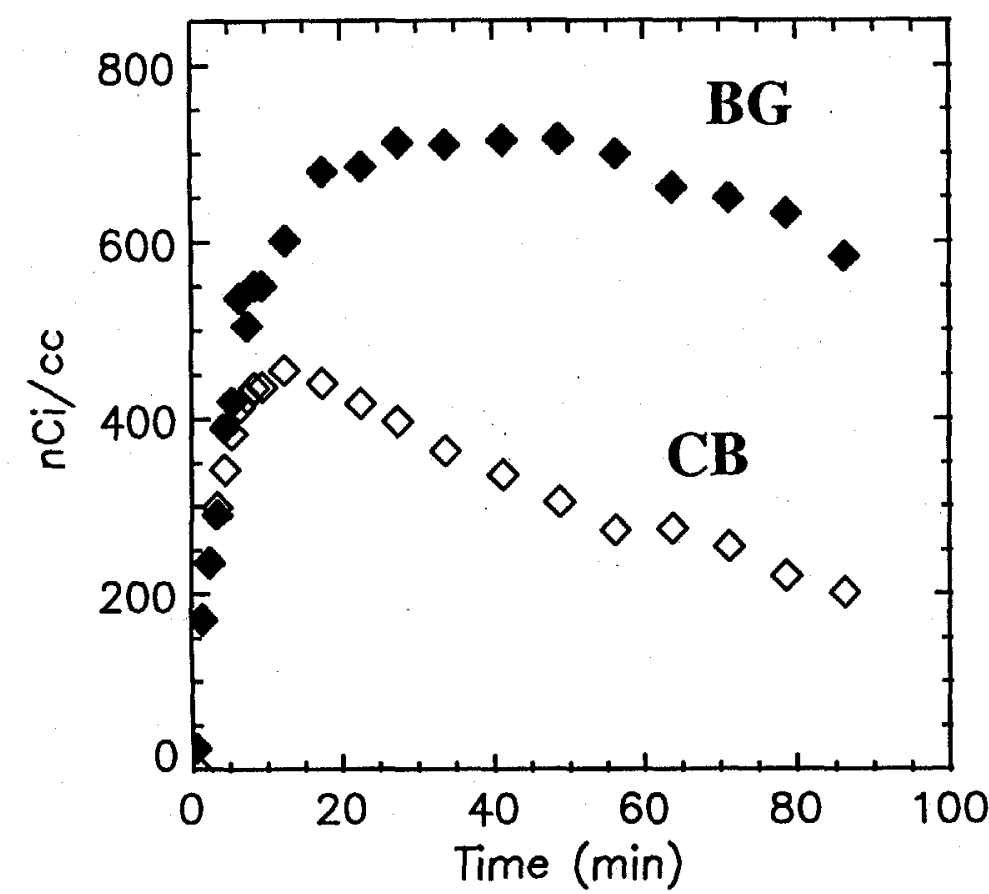

a.

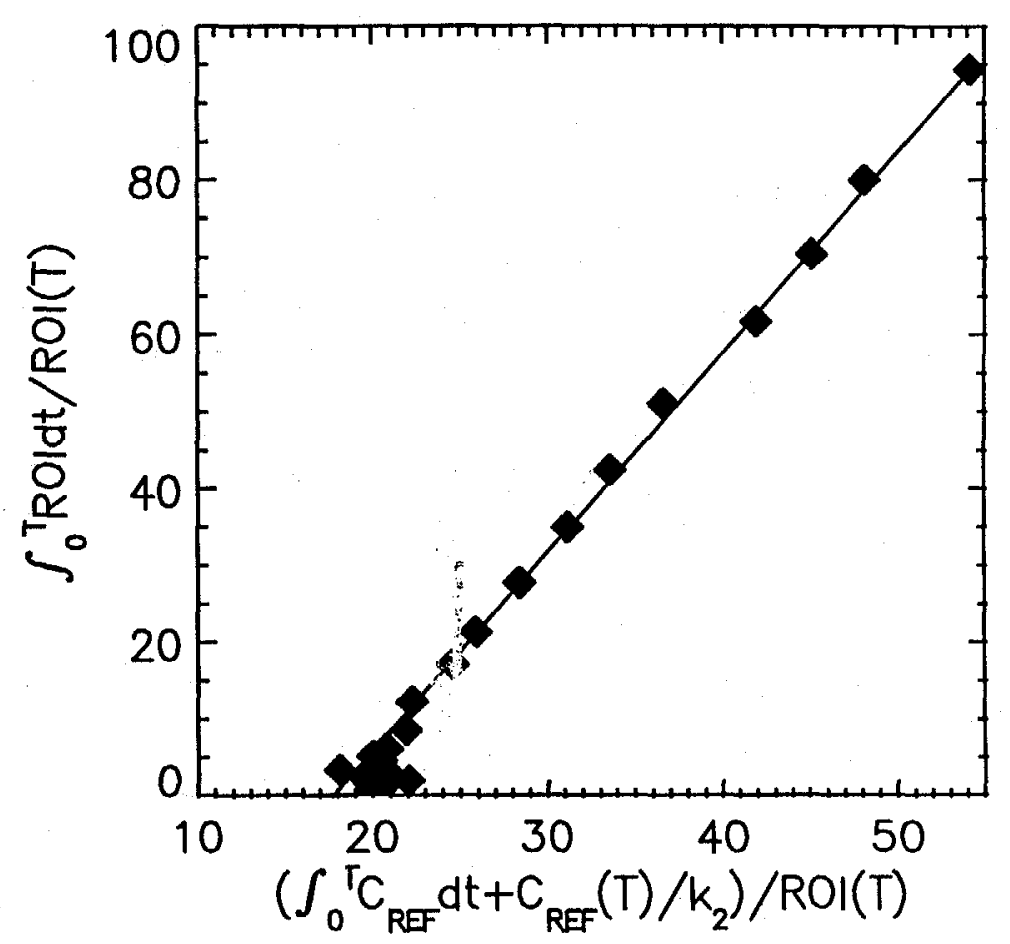

b.

Figure 4 

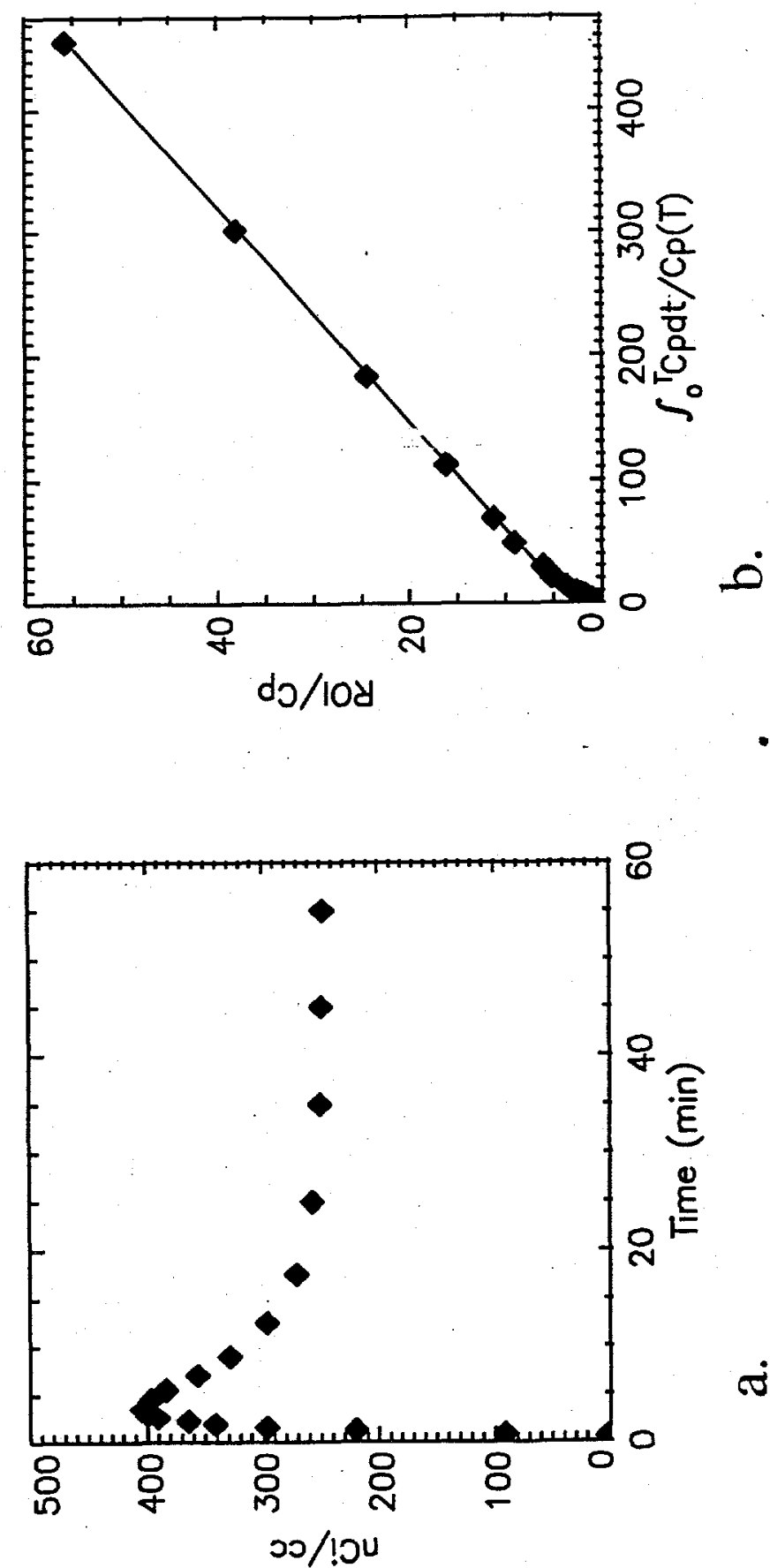


$$
C p \rightleftarrows S+E \rightleftarrows S-E \longrightarrow Y \longleftrightarrow \begin{aligned}
& E+P \\
& E_{\text {inact }}
\end{aligned}
$$

Enzyme inactivation

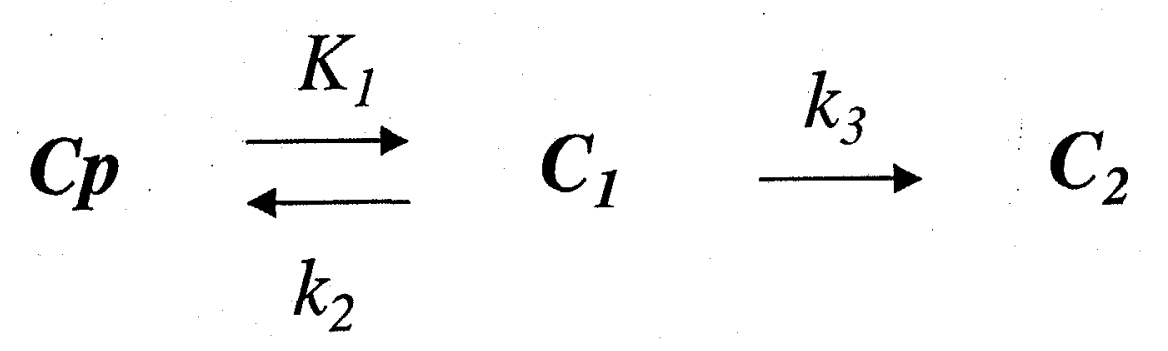

2 Tissue compartment irreversible model

$k_{3}$ is a composite of processes in enzyme inactivation 


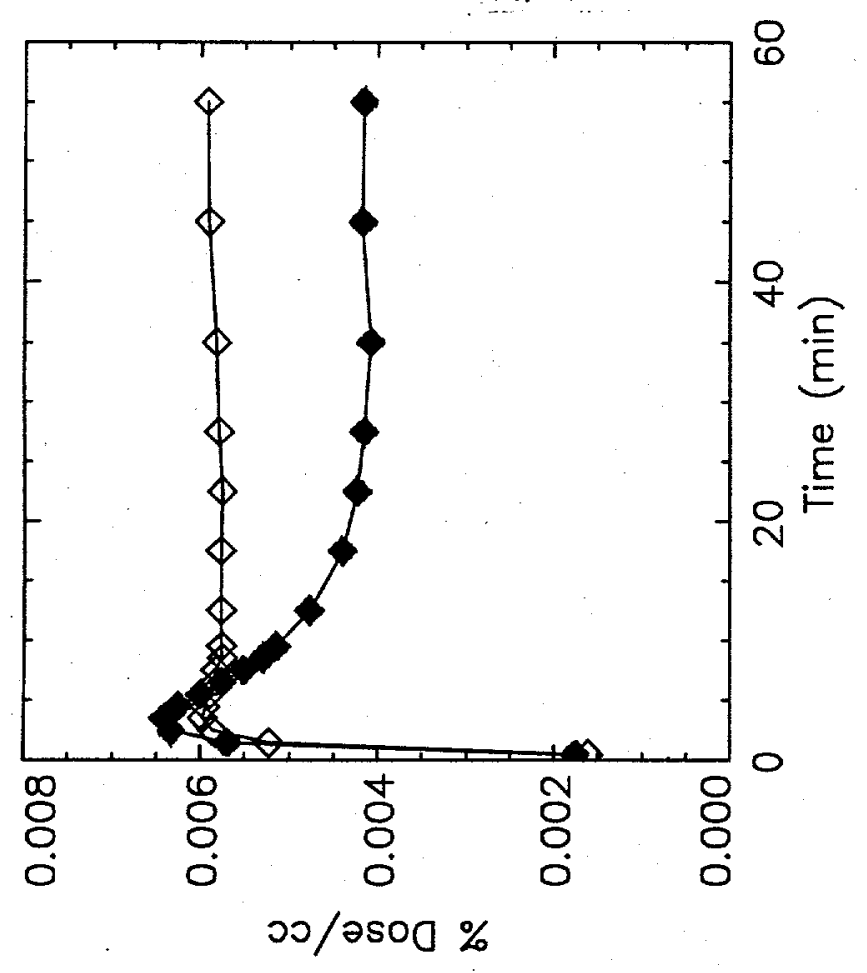

동 


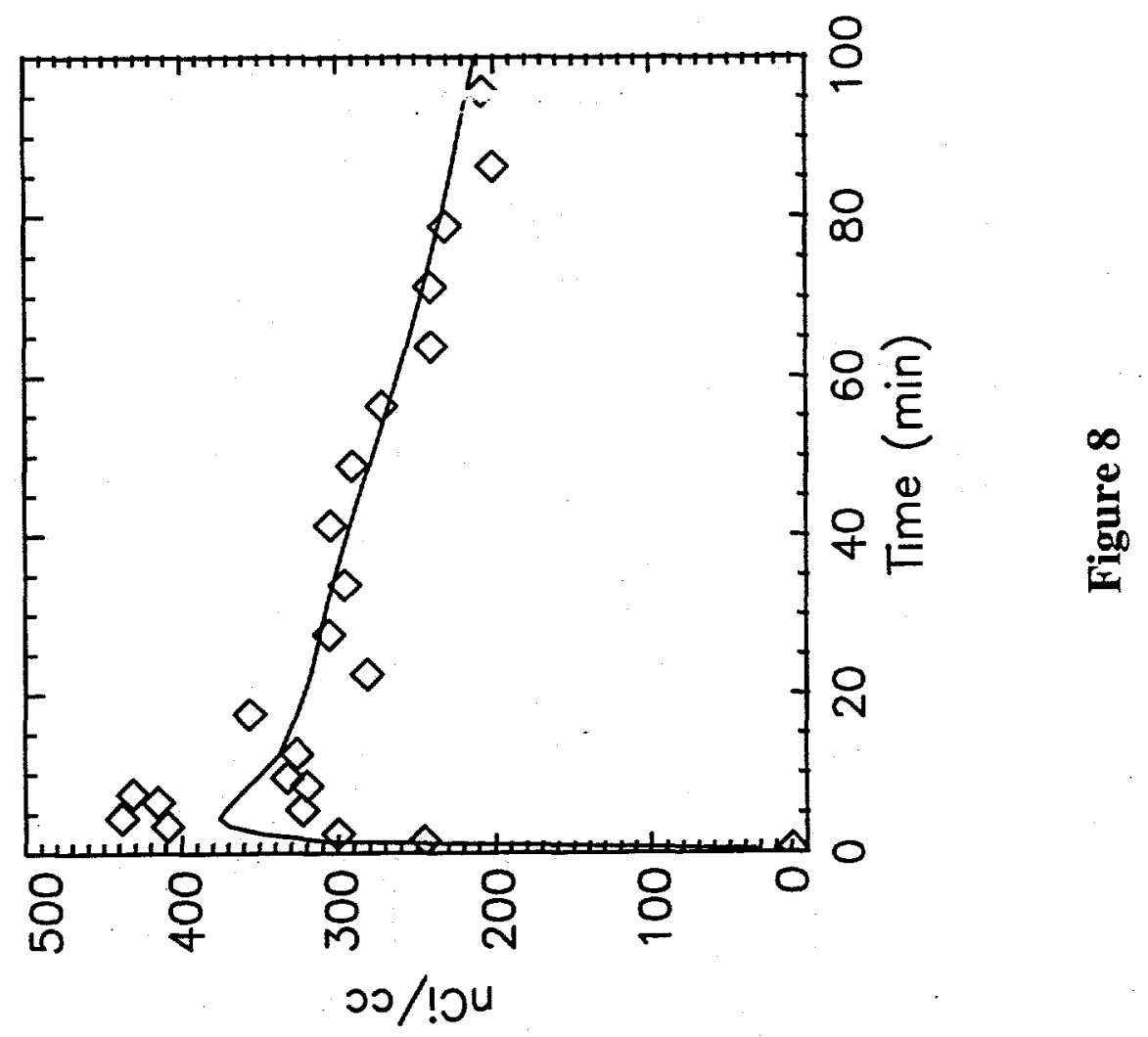




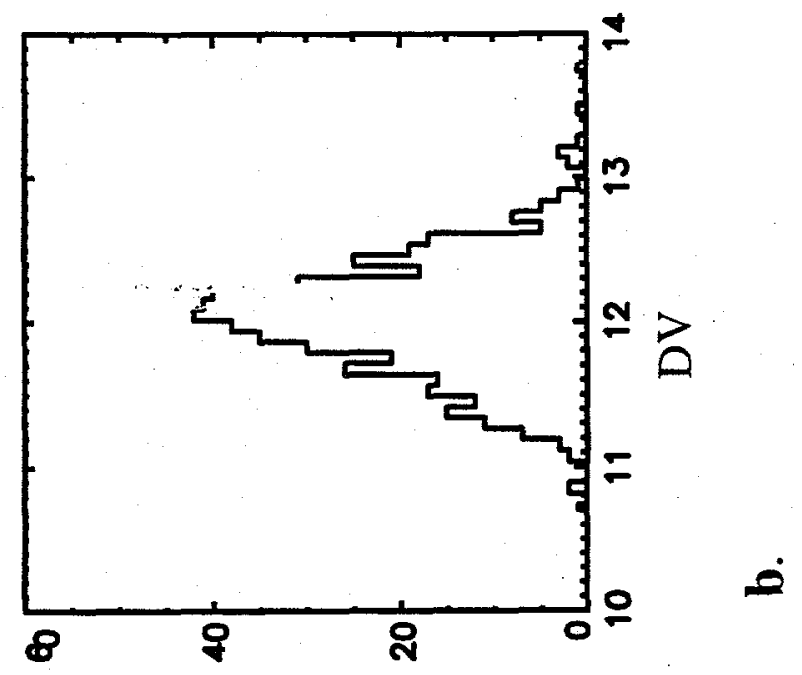

里

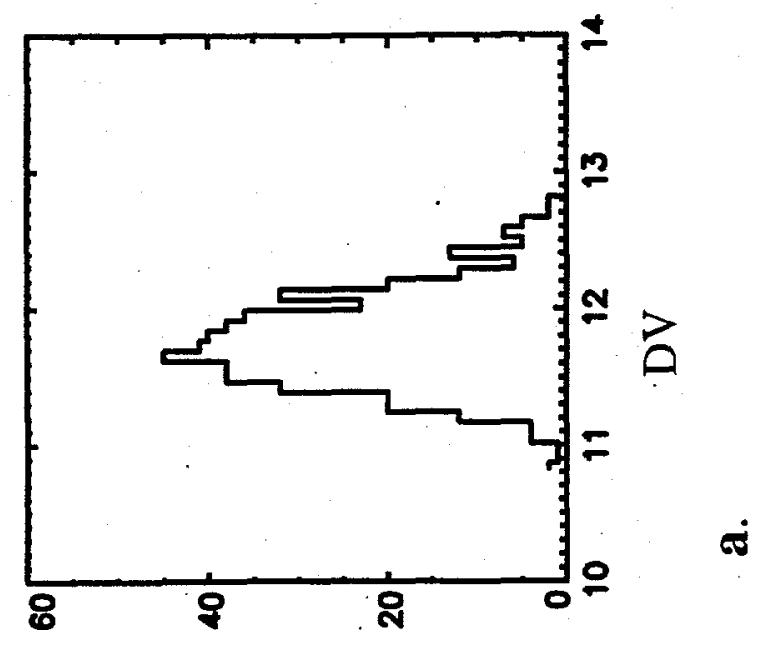



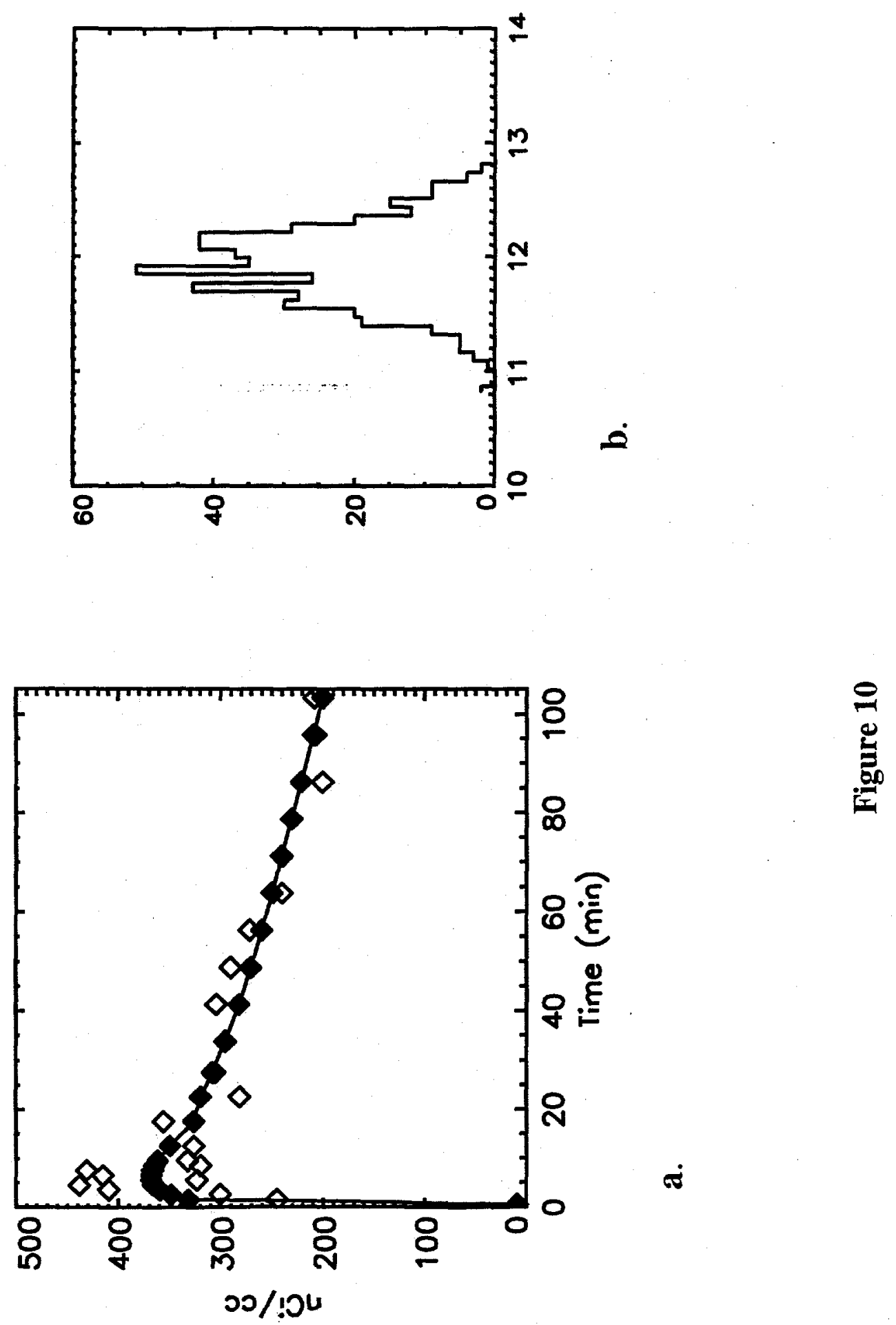
Table 1.

\begin{tabular}{|rll|}
\hline Time & $\mathrm{C}_{2} /\left(\mathrm{C}_{1}+\mathrm{C}_{2}\right)$ & $\left(\mathrm{C}_{1}+\mathrm{C}_{2}\right) / \mathrm{Cp}$ \\
\hline 35 & .72 & 52 \\
45 & .726 & 58 \\
55 & .73 & 64 \\
65 & .75 & 71 \\
75 & .752 & 77 \\
85 & .756 & 83 \\
105 & .76 & 87 \\
115 & .76 & 91 \\
\hline
\end{tabular}


กั

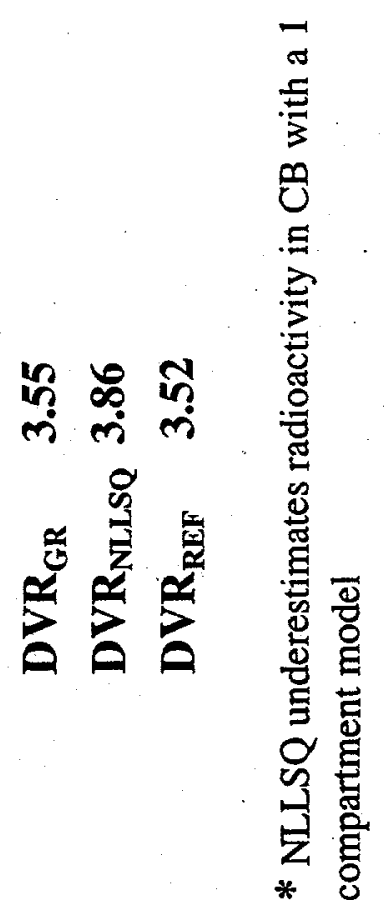


Table 3

$\begin{array}{lll} & \text { DV }_{\text {GR }} & \text { DV }_{\text {NLLSQ }} \\ \text { BG } & 27.7 & 27.9 \\ \text { CB } & 10.2 & 10.04 \\ & & \\ & & \\ & \text { DVR }_{\text {GR }} & \mathbf{2 . 7 2} \\ & \text { DVR }_{\text {NLLSQ }} & 2.78 \\ & \text { DVR }_{\text {REF }} & 2.59\end{array}$

Variation in DVR with $k_{\mathbf{2}}$

k2 DVR

$.03 \quad 2.78$

"True" $k_{2} \quad .04 \quad 2.70$

$\begin{array}{lll}\text { Average } k_{2} & .05 & 2.59\end{array}$

Without $k_{2} \quad 2.32$ 